\title{
Psychological distress among tsunami refugees from the Great East Japan earthquake
}

\author{
Robin Goodwin, Masahito Takahashi, Shaojing Sun and Menachem Ben-Ezra
}

\section{Background}

The 2011 Great Japan tsunami and nuclear leaks displaced 300000 people, but there are no large studies of psychological distress suffered by these refugees.

\section{Aims \\ To provide a first assessment of major factors associated with distress and dysfunctional behaviour following the disasters.}

\section{Method}

All refugee families living in Miyagi were sent a questionnaire 10-12 months after the disasters. 21981 participants (73\%) returned questionnaires. Questions assessed psychological distress (Kessler Psychological Distress Scale, K6), dysfunctional behaviours, demographics, event exposure, change in physical activity, household visitors and emotional support.

\section{Results}

Nine percent scored $13+$ on the $\mathrm{K} 6$ indicating risk of severe mental illness. Psychological distress was greater among
Fukushima refugees. Demographic variables, family loss, illness history and change in physical activity were associated with psychological distress and dysfunctional behaviours. Associations between psychological distress and dysfunction and visitors/ supporters depended on relation to supporter.

\section{Conclusions}

Practitioners need to recognise existing disease burden, community histories and family roles when intervening following disasters

\section{Declaration of interest}

None.

\section{Copyright and usage}

(C) The Royal College of Psychiatrists 2015. This is an open access article distributed under the terms of the Creative Commons Non-Commercial, No Derivatives (CC BY-NC-ND) licence.
The March 2011 Great East Japan (Tōhoku) earthquake measuring $9.0+$ on the Richter scale was the largest earthquake in Japanese history and one of the largest in recorded history. Despite a long history of earthquakes in the region, countermeasures proved insufficient against this event. ${ }^{1}$ The earthquake was accompanied by a tsunami $130 \mathrm{~km}$ off the coast of Miyagi Prefecture that killed more than 18000 people. Although other earthquakes have led to larger death tolls, the tsunami was remarkable in causing severe damage to the nuclear reactors in Fukushima, damaging all six and leading to meltdowns in three. ${ }^{2}$ This nuclear accident was subsequently rated 'Level 7 ' by the Japanese Ministry of Economy, Trade and Industry, making the Fukushima incident as of comparable severity to the 1986 Chernobyl incident.

Natural disasters, particularly severe events that directly affect large populations, are associated with a range of serious mental health problems, ${ }^{3}$ with mass population displacement disrupting routine social and economic activities ${ }^{4}$ and community bonds. ${ }^{5}$ However, compared with disasters elsewhere, we have relatively little knowledge about trauma reactions in Japan, and we know little about the mental health of the 335000 refugees displaced by the compound disasters of March 2011 or the major factors contributing towards their psychological stress or dysfunctional behaviours. In this paper, we report data from a survey of all refugees in Miyagi Prefecture, the prefecture (administrative region) most affected by the tsunami. ${ }^{6}$ Our sample also included refugees from the two other most affected prefectures: Iwate and Fukushima. ${ }^{7}$ (Fully or partially destroyed houses numbered 236134 in Miyagi, 24916 in Iwate and 74853 in Fukushima. ${ }^{7}$ ) We consider the relationship between psychological distress and sociodemographic factors associated with differential responses to following mass trauma (age, ${ }^{8}$ gender, ${ }^{9}$ family finances, ${ }^{10}$ significant loss (family fatalities, housing loss), ${ }^{11}$ disease-related vulnerabilities ${ }^{12}$ and opportunities for physical activity. ${ }^{13}$ Previous work has indicated that friends, relatives and spouses may provide the main sources of emotional support, and relatives and friends may provide greater tangible support. ${ }^{14}$ We include social support as an important resource against large-scale stressors, ${ }^{9,15,16}$ when recognising the role of different supporters in Japan. Because of the uneven distribution of losses across cities, and the varied distribution of families and communities during relocation, we analyse the association between support and psychological distress at multiple levels (city, family and individual). Taken together, this will help us provide a better understanding of those most at risk following a complex mass disaster and aid in designing future interventions for displaced refugees.

\section{Method}

\section{Design and participants}

Data for this study were from the Miyagi Prefectural Health Survey administered by the Miyagi Health Department 10-12 months after the earthquake (January-March 2012). In this crosssectional survey, Miyagi Prefecture distributed questionnaires to all 12828 refugee families living in rented accommodation paid for by the prefecture. 9413 families, comprising 21981 individual participants aged at least 18, returned the questionnaire (10 312 (47\%) male, mean age 51.7 years, s.d. $=18.53$, response rate $73 \%$ ). Responses were primarily by mail from individual households. Survey questions were partly derived from those previously used by large surveys administered by local government in Kobe/ Hyōgo ${ }^{17}$ and Niigata ${ }^{18}$ following earthquakes in those prefectures. Table DS1 in the data supplement provides survey items and response frequencies. 


\section{Measures}

\section{Risk of mental illness and dysfunctional behaviour}

All participants completed the Kessler Psychological Distress Scale (K6) (Japanese version, six items, $\alpha=0.91$ ), a screening scale for non-specific psychological distress. Scores of 8-12 indicate mildmoderate mental distress, $13+$ risk of severe mental illness. ${ }^{19}$ Dysfunctional behaviour was assessed with four items asking whether respondents currently suffered from each of the following: sleeplessness, lethargy, lack of appetite and drinking alcohol in the morning (each yes/no).

\section{Demographic variables and exposure to the disaster}

All participants indicated their age, gender, and city and prefecture at the time of the earthquake. They also indicated whether they had had a previous serious illness (yes/no), and whether they were currently receiving treatment for disease (yes/ no). These diseases were then coded into one of seven main categories: diabetes, high blood pressure, cancer, cardiac disease, cerebrovascular disease, respiratory disorder or disease requiring dialysis. Damage to the original house (complete collapse $v$. partial or no damage), major source of household income (salaried or otherwise) and loss of family members (yes/no) were recorded by one household member.

\section{Support and exercise following the disasters}

All respondents indicated whether their physical activity levels had decreased, stayed the same or increased since the earthquake. They also listed who, if anyone, could provide emotional support following the disasters (spouse, father, mother, grandparent, child, grandchild, sibling, friend; "who is your shoulder to cry on? (e.g. child, friend)' each scored yes or no). One member of the household recorded presence of visitors to the household (yes/no) and nature of that visitor (child, sibling, daughter-in-law; each yes/no).

\section{Analyses}

Significant independent variables were identified from bivariate regression analysis, using SPSS version 20.0 (Table 1 and Table DS3 in the data supplement). Regional differences in general distress were assessed through one-way ANOVA, controlling for age and gender; regional variations in family death, house loss and functional problems by chi-squared and logistic regressions. Hierarchical logistic regression compared those at risk of moderate/severe mental illness from those at lower risk and those who exhibited one or more dysfunctional behaviours (sleeplessness, lethargy, lack of appetite or alcohol use in the mornings) $v$. those showing none. To assess the relationship between distress and individual support, 'group-level' support (through household visits) and city-level variations, we conducted a nested analysis using multilevel modelling analysis ${ }^{20}$ (SAS version 9.2) controlling for age, gender, salaried employment and family loss. This enabled us to simultaneously assess the relative effects of these individual, group and city-level variables on distress, and the way in which individual support was associated with distress across families and cities. Table DS2 in the data supplement provides towns included in the analysis. Two-sided $P<0.05$ indicated significance throughout.

\section{Results}

\section{Disaster experience}

Demographic characteristics and post-disaster experiences are summarised in Table DS1 in the data supplement. Respondents lived primarily in Miyagi Prefecture at the time of the tsunami;

\begin{tabular}{|c|c|c|c|c|c|}
\hline & Unit/contrast & $B$ & s.e. & $\beta$ & $P$ \\
\hline \multicolumn{6}{|l|}{ Demographic and risk factors } \\
\hline Age & Years & 0.04 & 0.00 & 0.14 & $<0.0001$ \\
\hline Gender & Female & 1.21 & 0.07 & 0.12 & $<0.0001$ \\
\hline Unemployed & Yes & 1.67 & 0.08 & 0.16 & $<0.0001$ \\
\hline Previous serious disease & Yes & 2.14 & 0.09 & 0.17 & $<0.0001$ \\
\hline \multicolumn{6}{|l|}{ Disaster-related factors } \\
\hline Family loss in disaster & Yes & 0.65 & 0.11 & 0.04 & $<0.0001$ \\
\hline House collapse & Yes & 0.13 & 0.09 & 0.01 & 0.16 \\
\hline Currently receiving treatment & Yes & 2.09 & 0.07 & 0.20 & $<0.0001$ \\
\hline Diabetes & Yes & 1.47 & 0.15 & 0.07 & $<0.0001$ \\
\hline High blood pressure & Yes & 1.08 & 0.09 & 0.08 & $<0.0001$ \\
\hline Cancer & Yes & 2.75 & 0.29 & 0.07 & $<0.0001$ \\
\hline Cardiac disease & Yes & 2.23 & 0.20 & 0.08 & $<0.0001$ \\
\hline Cerebrovascular disease & Yes & 2.25 & 0.31 & 0.05 & $<0.0001$ \\
\hline Respiratory disorder & Yes & 2.20 & 0.23 & 0.07 & $<0.0001$ \\
\hline Dialysis & Yes & 1.64 & 0.82 & 0.01 & $<0.05$ \\
\hline Change in physical activities & Increase & -2.04 & 0.06 & -0.23 & $<0.0001$ \\
\hline House visitor & Yes & -1.68 & 0.12 & -0.11 & $<0.0001$ \\
\hline Visitor is relative & Yes & -1.13 & 0.09 & -0.09 & $<0.0001$ \\
\hline Visitor is child & Yes & 0.36 & 0.11 & 0.03 & $<0.001$ \\
\hline Visitor is sibling & Yes & -0.26 & 0.09 & -0.02 & $<0.01$ \\
\hline Visitor is daughter-in-law & Yes & -0.21 & 0.23 & 0.01 & 0.36 \\
\hline \multicolumn{6}{|l|}{ Emotional support from } \\
\hline Spouse & Yes & -1.03 & 0.09 & -0.09 & $<0.0001$ \\
\hline Father & Yes & -1.96 & 0.22 & -0.07 & $<0.0001$ \\
\hline Mother & Yes & -1.17 & 0.16 & -0.05 & $<0.0001$ \\
\hline Child & Yes & 0.70 & 0.14 & 0.04 & $<0.0001$ \\
\hline Sibling & Yes & 0.10 & 0.15 & 0.01 & 0.50 \\
\hline Friend & Yes & -1.13 & 0.09 & -0.09 & $<0.0001$ \\
\hline
\end{tabular}


935 respondents (4.3\%) lived elsewhere, largely in Fukushima. Eighty per cent experienced the complete collapse of their house, but household losses varied by region. Respondents in Northern Miyagi were most likely to report complete household collapse and family deaths; those in Fukushima the least likely (respective $\left.\chi^{2}(2)=3651, P<0.001 ; \chi^{2}(1)=103.19 ; P<0.001\right)$. Almost two-fifths of respondents were unemployed at the time of the survey (39.7\%), with company employees the largest employed group (24.2\%). Regarding pre-existing vulnerabilities, $21.5 \%$ reported having had a previous serious disease, whereas $39.2 \%$ were currently being treated for a disease, with high blood pressure (20.3\%) and diabetes (6.1\%) the most commonly cited. Nearly half $(49.9 \%)$ had seen a decrease in their physical activity since the earthquake, with only $5.4 \%$ reporting increased activity. Most respondents $(88 \%)$ had received a house visitor since the disaster with most of these visitors (79\%) a relative. The most frequent supporters were the spouse (mentioned by $27 \%$ ), a sibling (24\%) or a friend $(21 \%)$.

\section{Psychological distress}

Approximately $9 \%$ of respondents scored $\geq 13$ on distress (high risk of severe mental illness) and 18\% scored 8-12 (moderate risk of mental distress). Psychological distress was higher in Fukushima (mean 5.57) than southern Miyagi (5.31) or northern Miyagi (5.04) $(F(2,20300)=16.7, P<0.0001$, all contrasts $P<0.001)$. Older respondents, females and those without employment reported higher psychological stress, as did those who lived in a household with a family death, those with no visitors, participants with a previous serious disease, those currently under treatment, respondents who reported decreased physical activities since the tsunami and those who received support from a child (Table 1). Psychological distress was also positively associated with each disease category currently under treatment. Lower distress was associated with help from a spouse, parent or friend.

We differentiated those at risk of moderate or severe mental distress from those at lower risk (Table 2). The odds of having a mental disorder were significantly higher for women, the unemployed, respondents who had lost a family member in the disaster, participants with previous serious disease and those receiving current treatment. The odds of distress were significantly lower for respondents with support from their parent, spouse, child or friend and those visited by a sibling and those who had increased their physical activity.

\section{Dysfunctional behaviours}

Of four possible dysfunctional behaviours, respondents were most likely to report sleeplessness (18.3\%) or lethargy (10.9\%) and were less likely to state lack of appetite $(3.4 \%)$ or alcohol use in the morning (1.2\%). Respondents in southern Miyagi were more likely to report sleeplessness, lack of appetite and alcohol use in the mornings than their northern Miyagi counterparts. Older respondents, women, those with no job, no house visitor, reduced physical activity and no support from spouse, parent or friend were generally more likely to report functional problems, although family loss was associated only with greater lethargy (Table DS4 in the data supplement). Support from a child was related to greater dysfunction, having a child visit the home greater sleeplessness, whereas house collapse was largely unrelated to dysfunction. Home visits from a daughter-in-law were related to greater sleeplessness and morning alcohol use.

We differentiated those who exhibited no dysfunctional behaviours (73.3\%) from those who showed at least one dysfunction (Table 3). Odds of reporting at least one dysfunction were significantly higher for older respondents, women, unemployed, those with previous serious disease, those currently receiving

\begin{tabular}{|c|c|c|c|}
\hline & $B$ & Odds ratio & $95 \% \mathrm{Cl}$ \\
\hline \multicolumn{4}{|l|}{ Demographic and risk factors } \\
\hline Age & -0.00 & $1.00 * * *$ & $0.99-1.00$ \\
\hline Gender (female) & 0.34 & $1.41^{* * *}$ & $1.31-1.51$ \\
\hline Unemployed & 0.11 & $1.12^{\star \star}$ & $1.03-1.21$ \\
\hline Previous serious disease & 0.38 & $1.46^{* * *}$ & $1.34-1.59$ \\
\hline Currently receiving treatment & 0.46 & $1.59^{* * *}$ & $1.46-1.72$ \\
\hline \multicolumn{4}{|l|}{ Risk exposure } \\
\hline Family loss in disaster & 0.30 & $1.35^{* * *}$ & $1.22-1.50$ \\
\hline Collapse of house & -0.01 & 0.99 & $0.90-1.08$ \\
\hline Increase in activity & -0.62 & $0.54^{* * *}$ & $0.51-0.58$ \\
\hline \multicolumn{4}{|l|}{ Support } \\
\hline Visit from child & 0.08 & 1.08 & $0.96-1.21$ \\
\hline Visit from sibling & 0.21 & $0.81 * * *$ & $0.73-0.89$ \\
\hline Visit from daughter-in-law & 0.03 & 1.03 & $0.81-1.31$ \\
\hline Support from spouse & -0.41 & $0.67^{* * *}$ & $0.61-0.73$ \\
\hline Support from father & -0.42 & $0.65^{* *}$ & $0.49-0.88$ \\
\hline Support from mother & -0.22 & $0.80^{*}$ & $0.66-0.97$ \\
\hline Support from grandparent & 0.15 & 1.16 & $0.48-2.80$ \\
\hline Support from child & -0.20 & $0.82 * *$ & $0.71-0.94$ \\
\hline Support from grandchild & 0.14 & 1.15 & $0.49-2.72$ \\
\hline Support from sibling & -0.14 & 0.87 & $0.75-1.00$ \\
\hline Support from friend & -0.01 & $0.61 * * *$ & $0.55-0.67$ \\
\hline \multicolumn{4}{|c|}{$\begin{array}{l}\text { Reference category: risk of moderate/serious mental illness (Kessler Psychological } \\
\text { Distress Scale score } 8 \text { or above } n=4142 \text { ) } v \text {. } n=11820 \text { in the full model due to missing } \\
\text { data. Demographic and risk exposure variables were simultaneously entered. Support } \\
\text { variables are partially adjusted by demographic and risk exposure variables. Visit from } \\
\text { relative is not independent of visits listed so is not included. }\end{array}$} \\
\hline
\end{tabular}

\section{Table 3 Predictors of at least one dysfunctional behaviour}

\begin{tabular}{|c|c|c|c|}
\hline & $B$ & Odds ratio & $95 \% \mathrm{Cl}$ \\
\hline \multicolumn{4}{|l|}{ Demographic and risk factors } \\
\hline Age & 0.00 & $1.00 * * *$ & $1.00-1.00$ \\
\hline Gender (female) & 0.29 & $1.34^{* * *}$ & $1.25-1.43$ \\
\hline Unemployed & 0.28 & $1.32 * * *$ & $1.22-1.43$ \\
\hline Currently receiving treatment & 0.48 & $1.61 * * *$ & $1.48-1.75$ \\
\hline Previous serious disease & 0.32 & $1.37^{* * *}$ & $1.26-1.50$ \\
\hline \multicolumn{4}{|l|}{ Risk exposure } \\
\hline Family loss in disaster & 0.25 & $1.28 * * *$ & $1.16-1.42$ \\
\hline Collapse of house & -0.17 & $0.85^{\star * *}$ & $0.78-0.92$ \\
\hline Increase in activity & -0.78 & $0.46^{* * *}$ & $0.43-0.49$ \\
\hline \multicolumn{4}{|l|}{ Support } \\
\hline Visit from child & 0.01 & 1.00 & $0.90-1.13$ \\
\hline Visit from sibling & -0.16 & $0.85^{* * *}$ & $0.77-0.93$ \\
\hline Visit from daughter-in-law & 0.22 & 1.24 & $0.99-1.56$ \\
\hline Support from spouse & -0.29 & $0.75^{\star * *}$ & $0.69-0.82$ \\
\hline Support from father & -0.33 & $0.72^{\star}$ & $0.53-0.97$ \\
\hline Support from mother & -0.22 & $0.81 *$ & $0.66-0.98$ \\
\hline Support from grandparent & -0.48 & 0.62 & $0.21-1.84$ \\
\hline Support from child & -0.18 & $0.84^{* *}$ & $0.73-0.96$ \\
\hline Support from grandchild & 0.49 & 1.63 & $0.73-3.67$ \\
\hline Support from sibling & -0.04 & 0.96 & $0.84-1.11$ \\
\hline Support from friend & -0.39 & $0.68^{* * *}$ & $0.62-0.74$ \\
\hline \multicolumn{4}{|c|}{$\begin{array}{l}\text { Reference category: none } v \text {. one or more dysfunctional behaviours. Demographic and } \\
\text { risk exposure variables were simultaneously entered. Support variables are partially } \\
\text { adjusted by demographic and risk exposure variables. Visit from relative is not } \\
\text { independent of visits listed so is not included. } \\
{ }^{\star} P<0.05,{ }^{* * P} P 0.01,{ }^{* * * P} P 0.001 \text {. }\end{array}$} \\
\hline
\end{tabular}

treatment and respondents who lost a family member during the tsunami. Respondents whose house had collapsed, had a visit from a sibling, support from a spouse, parent, child or friend were less likely to report a dysfunction. 


\begin{tabular}{|c|c|c|c|c|c|}
\hline & $\begin{array}{l}\text { Three-level } \\
\text { unconditional }\end{array}$ & $\begin{array}{l}\text { Two-level } \\
\text { unconditional }\end{array}$ & $\begin{array}{l}\text { Two-level fixed level-1 } \\
\text { predictors }\end{array}$ & $\begin{array}{l}\text { Two-level random } \\
\text { intercept and slope } \\
\text { model }\end{array}$ & $\begin{array}{c}\text { Two-level random model } \\
\text { with fixed level-1 and level- } \\
2 \text { predictors }\end{array}$ \\
\hline Fixed-effects intercept & $0.887^{* * *}(0.017)$ & $0.886^{* * *}(0.008)$ & $0.564^{* * *}(0.022)$ & $0.553^{* * *}(0.021)$ & $0.920^{\star * *}(0.036)$ \\
\hline \multicolumn{6}{|l|}{ Individual-level predictors } \\
\hline Age & & & $0.006^{* * *}(0.000)$ & $0.007 * * \star(0.000)$ & $0.006^{* * *}(0.000)$ \\
\hline Gender (male) & & & $0.201 * * *(0.010)$ & $0.207 * * *(0.010)$ & $0.207^{* * *}(0.010)$ \\
\hline Support from spouse & & & $-0.157^{\star * *}(0.015)$ & $-0.155^{\star * \star}(0.014)$ & $-0.133^{* * *}(0.015)$ \\
\hline Support from father & & & $-0.143^{* * *}(0.038)$ & $-0.146^{* * *}(0.037)$ & $-0.141^{* * *}(0.038)$ \\
\hline Support from mother & & & $-0.034(0.028)$ & $-0.036(0.027)$ & $-0.028(0.028)$ \\
\hline Support from child & & & $-0.101^{\star \star *}(0.023)$ & $-0.100 * * *(0.025)$ & $-0.082^{\star \star}(0.026)$ \\
\hline Support from sibling & & & $-0.074 * *(0.023)$ & $-0.076 * *(0.023)$ & $-0.067^{\star \star *}(0.025)$ \\
\hline Support from friend & & & $-0.164^{\star * *}(0.015)$ & $-0.167^{* * *}(0.015)$ & $-0.157^{\star \star \star}(0.015)$ \\
\hline \multicolumn{6}{|l|}{ Family-level predictors } \\
\hline Family loss & & & & & $0.182^{\star * \star}(0.025)$ \\
\hline Visitor to home & & & & & $-0.333^{* * *}(0.025)$ \\
\hline Salaried household & & & & & $-0.139 * * *(0.020)$ \\
\hline \multicolumn{6}{|l|}{ Random variance } \\
\hline Level-1 intercept & $0.375^{\star * *}(0.005)$ & $0.376^{* * *}(0.005)$ & $0.346 * * *(0.005)$ & $0.303^{* * *}(0.006)$ & $0.305^{* * *}(0.006)$ \\
\hline Level-2 intercept & $0.407^{\star * \star}(0.010)$ & $0.409 * * *(0.010)$ & $0.397 * * *(0.010)$ & $0.264 * * *(0.012)$ & $0.248^{* * *}(0.013)$ \\
\hline Level-3 intercept & $0.003(0.002)$ & & & & \\
\hline Age & & & & $0.000^{* * *}(0.000)$ & $0.000^{* * *}(0.000)$ \\
\hline Gender & & & & $0.066^{* * *}(0.010)$ & $0.061^{* * *}(0.010)$ \\
\hline Support from child & & & & $0.040(0.025)$ & $0.056^{*}(0.027)$ \\
\hline Support from sibling & & & & $0.020(0.023)$ & $0.032(0.025)$ \\
\hline \multicolumn{6}{|l|}{ Model fit } \\
\hline AlC & 44944.7 & 45214.0 & 40725.6 & 40288.3 & 36570.8 \\
\hline $\mathrm{BIC}$ & 44949.4 & 45228.2 & 40739.7 & 40330.7 & 36612.7 \\
\hline$-2 * \log$ likelihood & 44938.7 & 45210.0 & 40721.6 & 40276.3 & 36558.8 \\
\hline
\end{tabular}

\section{Modelling support across individuals, families and cities}

Because of potential variations in the impact of support on psychological distress across families and locations, we modelled the association between individual support and psychological distress taking into account variations across families (family death, employment, visitors to the household) and city at time of tsunami.

City explained only a small amount of total variance in the data (inter-class correlation 0.004). Consequently, we contrasted two-level models considering individual- and family-level variations in distress (Table 4). The best model was a random model with fixed level-1 and level-2 predictors, with an unconditional two-level model attributing $47.9 \%$ of the total variance to individual-level factors, and $52.1 \%$ to family-level variables. This showed that, at the individual level, being male and having support from a friend were most strongly associated with lower levels of distress; at the family level having a family visitor was most significantly associated with less distress, with all the familylevel variables having a statistically significant effect when controlling for individual characteristics. Age, gender and social support from a child all demonstrated a statistically significant random effect, suggesting that these variables differentially influence distress across families.

\section{Discussion}

To the best of our knowledge, this is the first large-scale study to examine factors associated with the psychological distress of refugees following a complex (multisource) disaster, in this case combining an earthquake, tsunami and nuclear leak. Despite considerable loss of resources (with more than $80 \%$ of people completely losing their house), the refugees in our study exhibited low levels of general psychological distress 10-12 months postdisaster. Distress was similar to that reported in a Californian general community sample, ${ }^{21}$ and only a minority of our respondents reported functional difficulties. This may result from familiarity with natural disasters in Japan - more than $20 \%$ of the world's largest earthquakes occur in or around Japan. ${ }^{4}$ Such familiarity can inoculate against new events and help foster a cultural belief in shouganai (it cannot be helped), enabling individuals and communities to absorb losses and maintain psychological well-being. ${ }^{22}$ It may also reflect findings elsewhere showing only a minority of those exposed to a disaster suffer psychological distress. ${ }^{10}$ Unlike in previous studies, loss of housing resources was only weakly associated with more severe psychological outcomes. ${ }^{22}$

\section{Vulnerable groups}

Despite the above there were important functional challenges for some groups of refugees. As elsewhere, both disease history and current disease treatment were associated with greater psychological distress, emphasising the need for particular support for individuals with physical ailments. This may result partly from a Japanese tendency for somatic presentation of mental distress. ${ }^{22}$ As in other Japanese research loss of family members during mass trauma was associated with distress. ${ }^{10}$

Distress and dysfunctional behaviour were also higher among older refugees. Although older age has been viewed as a protective factor, particularly among those with previous inoculation experiences, ${ }^{10}$ the majority of those killed in the tsunami were aged 
over 60. Compound stresses can rapidly overcome psychological resources, particularly for the frail or disabled. Older Japanese receive less informal support and find it more difficult to turn to health professionals than their younger counterparts. ${ }^{16}$ As elsewhere, family employment was a significant predictor of psychological distress and dysfunction, ${ }^{10,12,18}$ and the stresses of having to find new employment can be particularly onerous jobs for the elderly. ${ }^{5}$ Consistent with prior studies in Japan, ${ }^{13}$ a decline in health activity following mass trauma was associated with increased distress and dysfunctional behaviours. Higher levels of stress levels and greater dysfunction were evident among women, as elsewhere. ${ }^{12,18}$ This may result from their greater coping role following disaster. ${ }^{9}$

Different regions may experience stressors in different ways and suffer varying degrees of community disruption. Number of deaths in an area has been previously related to distress, ${ }^{4}$ but despite lower levels of family deaths ${ }^{7}$ residents from Fukushima reported greater distress than those from Miyagi. Several factors may contribute to this ${ }^{5}$ including the uncertainties and confusion associated with the radiation leak ${ }^{23}$ and the divisive influence of this uncertainty on family relations. ${ }^{5}$ Residents from Fukushima also had to deal with arguments over compensation, self-guilt about leaving friends and family, and discrimination in their new location, ${ }^{24}$ with radiation stigma associated with higher levels of post-traumatic stress in Fukushima. ${ }^{25}$ Those living in southern Miyagi reported greater distress and dysfunctional behaviours than those in the north, again despite less household destruction. The northern Miyagi coast has suffered many previous tsunamis, whereas the southern seacoast areas and Fukushima had not witnessed a tsunami for a thousand years. ${ }^{6}$ This may have reduced familiarity with the tsunami threat, and the lack of mountainous terrain for escape in the south may have accentuated anxiety and dysfunctional response.

\section{Social support}

As elsewhere, the Japanese prefer to turn for psychological support to families, friends and relatives rather than health professionals. ${ }^{22}$ Social support from family, friends and community members following a disaster can help bolster resilience against multiple stressors ${ }^{8,12,13}$ and can aid in the development of further social ties and altruism. ${ }^{4}$ Our results are consonant with reports elsewhere showing the negative impact of social network disruption on mental health following an earthquake. ${ }^{18}$ Support might be of particular importance at key historical points (e.g. following the anniversary of the event, when anxiety may be heightened ${ }^{22}$ ). Particular supporters are likely to provide different forms of support (friends, relatives and spouses provide emotional support; relatives and friends tangible aid). ${ }^{14}$

Overall our data demonstrated the positive impact of household visitors and key emotional supporters on psychological health following disaster. Nevertheless, as other data from the Great Japan earthquake show, supporters themselves may be doubly stressed by their dual role of support provider and survivor. ${ }^{26}$ Japanese values of patience and accepting hardship ${ }^{27}$ are also accompanied by an unwillingness to publicly disclose emotions, at least to some. ${ }^{22}$ Notably in our data, some family relations were less able to provide positive support. Having a child or daughter-in-law visit the home was associated with greater sleeplessness, home visits from a daughter-in-law greater morning alcohol use. The negative effects of daughter-in-law visits may reflect a survival disadvantage for Japanese cared for by this relation (the 'daughter-in-law penalty'), ${ }^{28}$ as well as a Confucian sense of shame associated with receiving help from younger generations. This suggests social connections may not always be protective, and that too much emotional disclosure to some can be sometimes damaging. ${ }^{4}$ In univariate analyses, support from a child was related to greater distress and dysfunction but in multivariate analyses controlling for demographics and risk exposure this effect was reversed, suggesting suppressor variables. Indeed, multilevel analysis indicated that the impact of support from a child on distress varied significantly between families when family death, economic situation and visitors to the household were included. This underlines the need for further multilevel modelling of support among potentially vulnerable providers following disasters.

\section{Limitations, implications and future research}

We recognise several limitations to our study. Although widely used in Japan, 'Western' screening scales (such as the K6) may provide conservative estimates of distress compared with clinical interviews. $^{22}$ As a consequence, such scales may misrepresent relationships between symptoms and daily functioning. Data were self-reported, meaning we cannot always be certain about the identity of the respondent completing the scales and our study was cross-sectional, with no baseline or longer-term outcome measures, limiting our ability to infer causality. For example, although social support may predict decrease psychological distress in the first year after a disaster, it may be the psychological distress that then predicts availability of social support in later years. ${ }^{29}$ As is common with large postal surveys, questions were necessarily restricted and offered only a limited range of responses (e.g. on household loss). Data were available on only a limited number of socio-contextual factors and further research could include other variables such as biological markers of illness or more detailed medical histories. One promising area for future research is the mental health consequences of practising the Japanese cultural concept of 'tsunami tendenko' - prioritising self-preservation and not stopping to help others following a tsunami. Although this has been attributed to the saving of many lives following the disasters, a failure to help others may contradict the collective priorities of Japanese citizens. ${ }^{30}$

Our findings have a number of implications. First, in focusing on providing economic and housing support governmental agencies often neglect the mental health of survivors. ${ }^{13}$ However, stressors following a trauma are likely to have a range of societal impacts, including increased rates of sickness absence, ${ }^{31}$ and somatisation of stress may increase the burden on hospitals following major trauma. Those with a history of illness or present ailments may need particular help from health professionals, and loss of employment is also associated with less resilience postdisaster. ${ }^{12}$ Refugees may benefit from increased opportunities to participate in physical activity. Social support from family and friends is also likely to be important: intervention programmes focusing on vulnerable sections of the community (e.g. age or gender groups) and building on existing community ties are likely to be most efficacious. ${ }^{4,32}$ This may require relocation of families and communities to similar locations to complement existing social support networks. ${ }^{4}$ At the same time, some family relations (particularly the more vulnerable) may be less suitable to provide support and need particular attention following mass trauma.

Regional differences in distress and dysfunction also suggest an urgent need to reduce the uncertainty surrounding the Fukushima incident. Regard must be taken of the distrust towards 'official' messages following nuclear leaks, ${ }^{24}$ with a need to identify trusted expert communicators ahead of any future incidents. ${ }^{32}$ Particular care needs to be taken with internet coverage, with one study in Western countries showing associations between internet use and sleep disturbances and subclinical post-traumatic stress following the Fukushima disaster. ${ }^{33}$ 
A growing increase in natural disasters worldwide makes it essential to understand both tangible and emotional determinants of post-disaster psychological functioning. Our data from refugees of the Japanese tsunami show no simple relationship between housing loss and distress and functioning, with those who reported house collapse actually less likely to report at least one dysfunctional behaviour. Instead our findings emphasise the importance of pre-existing illness and family and community histories - and in particular emotional support provision - in aiding resilience and recovery. At the same time multilevel analysis suggests that not all supporters are associated with reduced psychological distress, and the efficacy of such support is likely to vary across families. Findings also suggest the need for normalising routines among those whose physical activity was disrupted by the disasters, and regional variations in response underline the need to reduce uncertainty following incidents such as a nuclear leak, confronting myths and stigma associated with those from affected areas. Recognising these factors is likely to be important in tailoring community interventions both during and following crises.

Robin Goodwin, PhD, Department of Psychology, University of Warwick, Coventry,

UK; Masahito Takahashi, MA, Faculty of Humanities, Yamaguchi University,

Yamaguchi, Japan; Shaojing Sun, PhD, School of Journalism, Fudan University,

Shanghai, China; Menachem Ben-Ezra, PhD, School of Social Work, Ariel University, Ariel, Israel

Correspondence: Professor Robin Goodwin, PhD, Department of Psychology, University of Warwick, Coventry CV4 7AL, UK. Email: robin.goodwin@warwick.ac.uk

First received 17 Feb 2015, final revision 30 Jun 2015, accepted 6 Aug 2015

\section{Acknowledgements}

We thank Miyagi Prefecture, Japan, for providing access to data for the purpose of this study.

\section{References}

1 Mori N, Takahashi T, Yasuda T, Yanagisawa, H. Survey of 2011 Tohoku earthquake tsunami inundation and run-up. Geophys Res Lett 2011; 38, doi:10.1029/ 2011GL049210.

2 National Police Agency of Japan. Damage situation and police counter measures associated with the 2011 Tohoku district earthquake. National Police Agency of Japan, 2012 (http://www.npa.go.jp/archive/keibi/biki/higaijokyo_e.pdf).

3 Norris FH, Tracy M, Galea, S. Looking for resilience: understanding the longitudinal trajectories of responses to stress. SOC Sci Med 2009; 68: 2190-8.

4 Matsubayashi T, Sawada Y, Ueda M. Natural disasters and suicide: evidence from Japan. Soc Sci Med 2013; 82: 126-33.

5 Maeda M, Oe M. Disaster behavioral health: psychological effects of the Fukushima nuclear power plant accident. In Radiation Disaster Medicine (eds K Tangawa, RK Chhem): 79-88. Springer, 2014.

6 Shibahara S. The 2011 Tohuku earthquake and devastating tsunami. Tohuku J Exp Med 2011; 223: 305-7.

7 Kitamura T, Kiyohara K, Iwami T. The Great East Japan Earthquake and out-ofhospital cardiac arrest. N Engl Med J 2013; 369: 2165-6.

8 Kaniasty K, Norris FH. Distinctions that matter: received social support, perceived social support, and social embeddedness after disasters. In Mental Health Consequences of Disasters (eds Y Neria, S Galea, F Norris): 175-209. Cambridge University Press, 2009

9 Liang $Y$, Wang X. Developing a new perspective to study the health of survivors of Sichuan earthquakes in China: a study on the effect of post-earthquake rescue policies on survivors' health-related quality of life. Health Res Policy Syst 2013; 11: 41.
10 Bonanno GA, Brewin CR, Kaniasty K, La Greca AM. Weighing the costs of disaster: consequences, risks, and resilience in individuals, families, and communities. Psychol Sci Publ Interest 2010; 11: 1-49.

11 Wickrama KAS, Kaspar V. Family context of mental health risk in Tsunami-exposed adolescents: findings from a pilot study in Sri Lanka. SOC SCi Med 2007; 64 713-23.

12 Bonanno GA, Galea S, Bucciarelli A, Vlahov D. What predicts psychological resilience after disaster? The role of demographics, resources, and life stress. J Consult Clin Psychol 2007; 75: 671-82.

13 Fukuda S, Morimoto K, Mure K, Maruyama S. Posttraumatic stress and change in lifestyle among the Hanshin-Awaji earthquake victims. Prev Med 1999; 29: 147-51.

14 Hayashi $\mathrm{H}$, Nishio $\mathrm{M}$. The evaluation of mental health care activities in the Hanshin-Awaji earthquake. In Study Report into Mental Health Care for Elderly after Large-size Natural Disaster (ed. Japan Red Cross): 179-188. Japan Red Cross, 1996.

15 Hobfoll SE. The influence of culture, community, and the nested-self in the stress process: advancing conservation of resources theory. Appl Psychol 2001; 50: 337-70.

16 Kwon Y, Maruyama S, Morimoto K. Life events and posttraumatic stress in Hanshin-Awaji earthquake victims. Environ Health Prevent Med 2001; 6: 97-103.

17 Hanshin Earthquake Survey Report. Report of the Survey on the Building Damages and Its Related Injuries in the Great Hanshin Earthquake. International Medical Center of Japan, 1995 (http://www.kananet.com/health/kobeqs.htm\#outline).

18 Nakamura K, Kitamura K, Someya T. Psychological recovery 5 years after the 2004 Niigata-Chuetsu earthquake in Yamakoshi, Japan. J Epidemiol 2014; 24: 125-31.

19 Kessler RC, Galea S, Gruber MJ, Sampson NA, Ursano RJ, Wessely S. Trends in mental illness and suicidality after Hurricane Katrina. Mol Psychiatry 2008; 13: 374-84.

20 Goldstein H. Multilevel Statistical Models (3rd edn). Edward Arnold, 2003.

21 Prochaska JJ, Sung H.-Y, Max W, Shi Y, Ong, M. Validity study of the K6 scale as a measure of moderate mental distress based on mental health treatment need and utilization. Int J Methods Psychiatr Res 2012; 21: 88-97.

22 Goto T, Wilson JP. A review of the history of traumatic stress studies in Japan. Trauma Violence Abuse 2003; 4: 195-209.

23 Rubin JG, Amlôt R, Wessley S, Greenberg N. Anxiety, distress and anger among British nationals in Japan following the Fukushima nuclear accident. Br J Psychiatry 2012; 201: 400-7.

24 Shigemura J, Tanigawa T, Saito I, Nomora S. Psychological distress in workers at the Fukushima nuclear power plants. JAMA 2012; 308: 667-9.

25 Ben-Ezra M, Shigemura J, Palgi Y, Hamama-Raz Y, Lavenda O, Suzuki M, et al. From Hiroshima to Fukushima: PTSD symptoms and radiation stigma across regions in Japan. J Psychiatr Res 2015; 60: 185-6.

26 Sakuma A, Takahashi Y, Ueda I, Sato H, Katsura M, Abe M, et al. Post-traumatic stress disorder and depression prevalence and associated risk factors among local disaster relief and reconstruction workers fourteen months after the Great East Japan Earthquake: a cross-sectional study. BMC Psychiatry 2015; 15: 58.

27 Lifton RJ. Death in Life: Survivors of Hiroshima. Random House, 1967.

28 Nishi A, Tamiya N, Kashiwaga M, Takahasi H, Sato M, Kawachi I. Mothers and daughters-in-law: a prospective study of informal care-giving arrangements and survival in Japan. BMC Geriatr 2010; 10: 61.

29 Kaniasty K, Norris FH. Longitudinal linkages between perceived social support and posttraumatic stress symptoms: sequential roles of social causation and social selection. J Trauma Stress 2008; 21: 274-81.

30 Yamori K. Revisiting the concept of tsunami Tendenko: tsunami evacuation behaviour in the Great East Japan Earthquake. J Disaster Res 2013; 8: 115-6.

31 Izutzu T, Shibuya M, Tsutsumi A, Konishi T, Kawamura N. The relationship between past traumatic experience and sickness absence. Int J Soc PSychiatry 2008; 54: 83-9.

32 Joffe H, Rossetto T, Solberg C, O'Connor C. Social representations of earthquakes: a study of people living in three highly seismic areas. Earthquake Spectra 2013; 29. 367-97.

33 Bui E, Rodgers RF, Herbert C, Franko DL, Simon NM, Birmes $\mathrm{P}$, et al. The impact of internet coverage of the March 2011 Japan earthquake on sleep and posttraumatic stress symptoms: an international perspective. Am J Psychiatry 2012; 169: $221-2$. 